\title{
Genetic analysis of adult plant, quantitative resistance to stripe rust in wheat cultivar 'Stephens' in multi-environment trials
}

\author{
M. Dolores Vazquez • C. James Peterson · Oscar Riera-Lizarazu • \\ Xianming Chen - Adam Heesacker · Karim Ammar • \\ Jose Crossa $\cdot$ Christopher C. Mundt
}

Received: 14 January 2011/ Accepted: 4 August 2011/Published online: 13 September 2011

(C) Springer-Verlag 2011

\begin{abstract}
The wheat (Triticum aestivum L.) cultivar 'Stephens' has been grown commercially in the USA Pacific Northwest for 30 years. The durable resistance of 'Stephens' to stripe rust (Puccinia striiformis f. sp. tritici) was believed to be due to a combination of seedling and adult plant resistance genes. Multilocation field trials, diversity array technology (DArT), and simple sequence repeat (SSR) markers were used to identify quantitative trait loci (QTL) for resistance. Recombinant inbred lines were assessed for stripe rust response in eight locations/ years, five in 2008 and three in 2009. The data from
\end{abstract}

Communicated by J. Snape.

Electronic supplementary material The online version of this article (doi:10.1007/s00122-011-1681-x) contains supplementary material, which is available to authorized users.

M. Dolores Vazquez $(\bowtie) \cdot$ C. James Peterson ·

O. Riera-Lizarazu · A. Heesacker

Department of Crop and Soil Science, Oregon State University,

Corvallis, OR 97331, USA

e-mail: m.dolores.vazquez@ oregonstate.edu

\section{Present Address:}

C. James Peterson

Limagrain Cereals Seeds, 3515 Richards Lake Road,

Fort Collins, CO 80524, USA

Present Address:

O. Riera-Lizarazu

International Crops Research Institute for the Semi-Arid Tropics

(ICRISAT), Patancheru 502324, Andhra Pradesh, India

X. Chen

US Department of Agriculture, Agricultural Research Service,

Wheat Genetics, Quality, Physiology, and Disease Research

Unit, Washington State University, Pullman,

WA 99164-6430, USA
Mt. Vernon, WA, differed from all other environments, and composite interval mapping (CIM) identified three QTL, QYrst.orr-1AL, QYrst.orr-4BS, and QYrpl.orr-6AL, which accounted for 12,11 , and $6 \%$ of the phenotypic variance, respectively. CIM across the remaining six environments identified four main QTL. Two QTL, QYrst.orr-2BS.2 and QYrst.orr-7AS, were detected in five of six environments and explained 11 and $15 \%$ of the phenotypic variance, respectively. Two other QTL, QYrst.orr- $2 A S$ and $Q Y$ rpl.orr- $4 B L$, were detected across four and three of six environments, and explained 19 and $9 \%$ of the phenotypic

\section{Chen}

Department of Plant Pathology,

Washington State University, Pullman,

WA 99164-6430, USA

K. Ammar · J. Crossa

International Maize and Wheat Improvement Center

(CIMMYT), Apartado Postal 6-641,

06600 Mexico D.F., Mexico

C. C. Mundt

Department of Botany \& Plant Pathology,

Oregon State University, Corvallis,

OR 97331-2902, USA 
variance, respectively. The susceptible parent 'Platte' contributed QYrpl.orr-4BL and QYrpl.orr-6AL, with the remaining QTL originating from 'Stephens'. For each environment, additional minor QTL were detected, each accounting for $6-10 \%$ of the phenotypic variance. Different QTL with moderate effects were identified in both 'Stephens' and 'Platte'. Significant QTL $\times$ environment interactions were evident, suggesting that specificity to plant stage, pathogen genotype, and/or temperature was important.

\section{Introduction}

Stripe rust (Puccinia striiformis Westend. f. sp. tritici Erik., $P s t)$ has received increased attention in North America since the appearance of more virulent and aggressive races detected in the past decade. These races caused yield losses even in areas where the disease was previously rarely detected and they are more threatening to wheat worldwide than the older races (Chen 2005; Hovmøller et al. 2008; Markell and Milus 2008; Milus et al. 2006, 2009). Host plant resistance is the most cost-effective and environmentally sound means of controlling stripe rust. Deployment of single, major genes for resistance is consistently compromised due to the genetic variability of the pathogen, emphasizing the need to breed for durable resistance. The soft white winter wheat cultivar 'Stephens' (Kronstad et al. 1978) has been widely planted for 30 years in the Pacific Northwest, USA, and has maintained durable resistance to stripe rust (Santra et al. 2008). High-temperature adult plant (HTAP) resistance genes are believed to have contributed significantly to the durability of 'Stephens' to stripe rust (Chen 2005; Chen and Line 1995a, Chen and Line 1995b; Santra et al. 2008).

Durable resistance to stripe rust is thought to be conferred by the additive effect of several minor genes ( $\mathrm{Lu}$ et al. 2009). It is often expressed only in the adult plant stage and when spring temperatures rise above a threshold level (Chen and Line 1995a). The presence of adult plant resistance is characterized by reduced rates of disease development resulting from longer latent periods, low infection frequencies, smaller uredinial size, and reduced duration and quantities of spore production due to frequent failure of haustorium formation ( $\mathrm{Li}$ et al. 2006; Milus et al. 2006; Niks and Rubiales 2002).

Screening, identifying, and understanding sources of disease resistance through the use of molecular markers are becoming routine tasks in breeding programs. This source of information aids in the decision-making process for performing crosses and maintaining lines for further evaluation. The objective of this work was to identify and locate QTL underlying genetic variability for stripe rust resistance across locations in a recombinant inbred line (RIL) population developed from a cross between 'Stephens' and the stripe rust susceptible line 'Platte'.

\section{Materials and methods}

Plant material and field analysis

The population for this study consisted of $156 \mathrm{~F}_{6}$-derived, $\mathrm{F}_{7}$ recombinant inbred lines (RILs) from a cross between 'Stephens' (a cultivar with moderate to high levels of adult plant resistance to stripe rust) and 'Platte' (a cultivar highly susceptible to stripe rust). 'Platte' was released in 1999 by HybriTech Seed International and has the pedigree Tesia79/Chatt'S'//Abilene (USDA-AMS 2009). 'Stephens' (CI 017596) is a cultivar released in 1978 in the Pacific Northwest (Kronstad et al. 1978), with the pedigree Pullman Selection 101/Nord-Desprez (Wheat Pedigree On Line 2009).

$\mathrm{F}_{6}$ seed harvested from the greenhouse was used to establish plots in the field. The parents and the RIL progeny were evaluated in the field in randomized complete blocks with two replications at five locations in 2008 and three locations in 2009. Locations for 2008 were: Toluca, Mexico (MX); Corvallis, Oregon (OR); Pendleton, OR; Pullman, Washington (WA) and Mt. Vernon (WA). In 2009, the locations were: Mt. Vernon, WA; Corvallis, OR; and Toluca, MX.

Plots consisted of two rows, $1 \mathrm{~m}$ long. The percent rust severity for each plot was evaluated according to the modified Cobb scale (Roelfs et al. 1992). Multiple readings were taken for each location. For all locations except Mt. Vernon, disease occurred only at the adult plant stage where first readings were taken after the susceptible parent showed $60-80 \%$ severity in the adult growth stage (GS) Zadoks 50-60 and the last readings were taken within the adult plant stage GS 70-80 (Supplementary Table 1). Initial readings at Mt. Vernon were taken at the early jointing stage (GS 30-31), when the susceptible parent showed around $80 \%$ severity and subsequent notes were taken at the adult plant stage around GS 55 when the susceptible parent showed $100 \%$ severity.

For all locations except Toluca, rust was established by natural infection. Artificial inoculation in Toluca was initiated about 4 weeks after planting by inoculating susceptible spreader rows. Two spreader rows were located at the beginning and end of each block. The suspension of rust urediniospores was in lightweight mineral oil (Sotrol $170^{\circledR}$ Chevron Phillips Chemical Company, The Woodlands, TX, USA) with the Pst isolate known as MX-94.11. This isolate and all of the detected races in Corvallis (12 in 2008 and 5 in 2009) and Pendleton (5 in 2008 and 4 in 2009) are 
Table 1 Mean ( \pm standard error), highest, and lowest disease severity score, coefficient of variation, and heritability on a plot basis $( \pm$ standard error) for parents and 156 recombinant inbred lines in each environment

\begin{tabular}{|c|c|c|c|c|c|c|c|c|}
\hline \multirow[t]{3}{*}{ Year } & \multirow[t]{3}{*}{ Location } & \multicolumn{5}{|c|}{ Stripe rust severity $(\%)$} & \multirow[t]{3}{*}{$h^{2}$} & \multirow{3}{*}{$\begin{array}{l}\text { Coefficient } \\
\text { of variation }\end{array}$} \\
\hline & & \multicolumn{2}{|c|}{ Parents } & \multicolumn{3}{|l|}{ RILs } & & \\
\hline & & Platte & Stephens & Mean & Min & Max & & \\
\hline \multirow[t]{5}{*}{2008} & Mt. Vernon & 100 & 2.0 & $45.0( \pm 9.8)$ & 1.0 & 100 & $0.78( \pm 0.03)$ & 31.28 \\
\hline & Whitlow & 37 & 6.0 & $27.9( \pm 7.5)$ & 0.5 & 70 & $0.51( \pm 0.05)$ & 37.4 \\
\hline & Toluca & 83 & 2.0 & $22.9( \pm 7.0)$ & 1.0 & 85 & $0.69( \pm 0.04)$ & 46.6 \\
\hline & Corvallis & 100 & 0.0 & $29.5( \pm 9.5)$ & 0.5 & 100 & $0.79( \pm 0.02)$ & 47.0 \\
\hline & Pendleton & 86 & 0.0 & $15.9( \pm 8.6)$ & 0.5 & 87 & $0.57( \pm 0.05)$ & 81.0 \\
\hline \multirow[t]{3}{*}{2009} & Mt. Vernon & 81 & 10.0 & $36.2( \pm 7.5)$ & 5.0 & 97 & $0.82( \pm 0.02)$ & 23.0 \\
\hline & Toluca & 50 & 9.0 & $21.1( \pm 6.1)$ & 5.0 & 50 & $0.41( \pm 0.06)$ & 41.2 \\
\hline & Corvallis & 100 & 2.0 & $50.0( \pm 8.0)$ & 0.5 & 100 & $0.64( \pm 0.04)$ & 29.0 \\
\hline
\end{tabular}

Disease severity scores were based on $\%$ leaf area covered by stripe rust on a plot basis. $P$ values were $<0.0001$ for genotype for all combinations of year and location

virulent on seedlings of 'Stephens'. At Mt. Vernon, the natural population was a mixture of 14 races (all virulent on seedlings of 'Stephens') in 2008 and 14 similar races in 2009 with 39 of 40 isolates virulent on seedlings of 'Stephens' (X.M. Chen and A. Wan, unpublished).

Molecular analysis and map construction

Parental and $\mathrm{F}_{6}$ plant DNA from young leaves were extracted using the DNeasy Plant DNA extraction kit (QIAGEN). DNA concentration was tested using a NanoDrop ND-1000 UV-vis Spectrophotometer. A final volume of $15 \mathrm{ng} / \mu \mathrm{L}$ was sent to Triticarte Pty. Ltd., Canberrra, Australia, to be genotyped with DArT (Diversity Array Technology) markers (Akbari et al. 2006). Additional simple sequence repeat (SSR) markers were screened for polymorphism between 'Platte' and 'Stephens' using approximately $50 \mathrm{ng}$ genomic DNA extracted from young leaves (Riera-Lizarazu et al. 2000). PCR amplifications were done using the recommended annealing temperature for the respective SSR markers. Visualization of the amplified SSR products was done using agarose gel electrophoresis (3\%) stained with ethidium bromide (Leonard et al. 2008). Once loci associated with the resistant parent were identified, additional SSR markers in the vicinity were selected using linkage maps available in the GrainGenes 2.0 database (2009).

Genotypic data from the 156 RILs were used to create a genetic linkage map with the software JoinMap v. 4.0 (Van Ooijen and Voorrips 2001). The original map was constructed using a total of 735 markers (681 DArTs and 54 SSRs), from which a subset of 161 markers (7 SSR and 154 DArT), spaced every $10 \mathrm{cM}$, were used to construct the 32 linkage groups, representing chromosomal areas from all common wheat chromosomes. Genetic distances were calculated using the Haldane function (Haldane 1919). For each linkage group, the best marker loci order was determined using maximum likelihood in Join Map 4.0.

Statistical and QTL analyses

The final disease reading for each location/year was used to perform all statistical and QTL analyses. This was done because the maximum number of QTL and the highest levels of phenotypic variance explained were identified in the final disease reading. Moreover, all QTL identified in early readings were also identified with the final reading.

The PROC GLM procedure in SAS version 9.1.3 (SAS Institute, Inc., Cary, NC, USA) was used to calculate least squares means. The PROC MIXED was used to calculate family heritability $\left(h^{2}\right)$ on a plot basis as $h^{2}=\sigma_{\mathrm{g}}^{2} / \sigma_{\mathrm{p}}^{2}=\sigma_{\mathrm{f}}^{2} /$ $\left(\sigma_{\mathrm{f}}^{2}+\sigma_{\mathrm{e}}^{2} / r\right)$, where the variance components are: $\sigma_{\mathrm{g}}^{2}$, genetic variance; $\sigma_{\mathrm{p}}^{2}$, phenotypic variance; $\sigma_{\mathrm{f}}^{2}$, family variance; $\sigma_{\mathrm{e}}^{2}$, error variance; and $r$, number of replications (Holland et al. 2003). For all tests, a probability level of $P<0.05$ was used.

Analyses across environments were done using the PROC MIXED procedure of SAS. The RILs, environments, and RILs $\times$ environment were considered to be fixed effects. The site regression (SREG) model (Yan and Kang 2003; Yang et al. 2009) was used to study genotype $\times$ environment interaction and it was fitted using the PROC MIXED procedure; the biplot of the first two components was employed to visualize the pattern of responses of RILs in environments.

Based on SREG results, two sets of data were used to perform separate QTL analyses. One dataset comprised Mt. Vernon results for 2008 and 2009. A second dataset was produced from the remaining six environments. QTL analysis was performed using composite interval mapping (CIM) in WinQTL Cartographer v.2.5 software (Wang 
et al. 2007). Window size was set at $10 \mathrm{cM}$ with five cofactors identified for each dataset section using forward and backward stepwise regression. Likelihood odds (LOD) thresholds for declaring statistical significance were calculated by 1,000 permutations (Churchill and Doerge 1994). Permutation thresholds for a type I error rate with a probability of 0.05 were 2.9 for each individual environment and 3.0 for data combined across environments. The additive effects $(a)$ and phenotypic coefficients of determination $\left(R^{2}\right)$ for individual QTL were estimated by CIM (Tang et al. 2006).

\section{Results}

Molecular analysis and map construction

The map with 161 markers, 7 SSR and 154 DArT, comprised 32 linkage groups, representing areas from the 21 chromosomes of common wheat and covering 1,786 cM. Final linkage groups were assigned to each chromosome with data from Triticarte's wheat map alignment (Triticarte 2009) and maps available on the GrainGenes 2.0 database (2009). The largest chromosome mapped was 2B with 224.5-cM and the shortest was 3D with 3.6-cM length.

Phenotypic values and statistical analysis

Significant disease levels were obtained in each location, with ratings for the susceptible parent 'Platte' ranging from $37 \%$ at Pullman to $100 \%$ at Corvallis and Mt. Vernon (Table 1). The resistant parent, 'Stephens' scored consistently low for stripe rust severity, ranging from 0 to a maximum of $10 \%$. Heritabilities $\left(h^{2}\right)$ were moderate to high depending on the environment, ranging from 0.41 in Toluca 2009 to 0.82 in Mt. Vernon 2009. Coefficients of variation (CVs) ranged as $23-81 \%$, likely due to variation in the magnitude of disease severity among environments. $P$ values indicated significant differences among genotypes for each environment (Table 1).

Disease severities of the RILs in each environment suggest a quantitative, rather than qualitative response to stripe rust (Supplementary Fig. 1). Responses were continuous with a higher preponderance of progeny with lower ratings. There was little indication of transgressive segregation, as severity ratings of RILs generally fell within parental values.

The biplot resulting from the SREG analysis explained $81 \%$ of the variance in RIL response to environments for disease severity. Environments were clustered based on genetic correlations in two groups: Mt. Vernon 2008 with Mt. Vernon 2009 versus all remaining environments (Fig. 1). The length of an environment vector indicates the

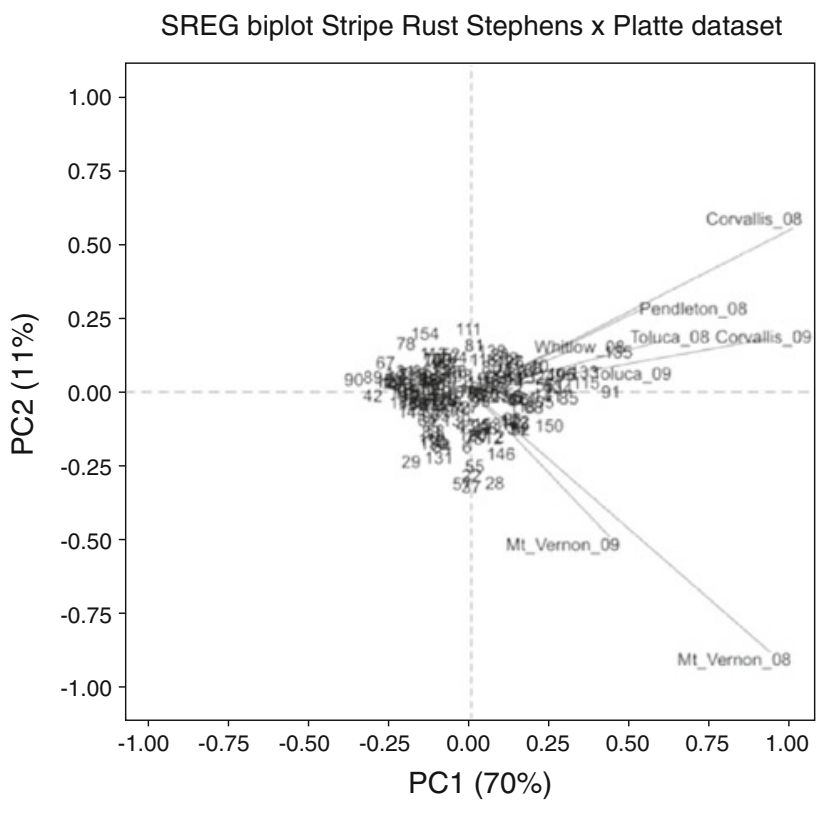

Fig. 1 Genotype and genotype $\times$ environment biplot based on an SREG model

magnitude of differences among genotypes for that specific environment.

QTL analysis: Mt. Vernon 2008 and 2009 dataset

The QTL that contributed to disease resistance at Mt. Vernon were located on chromosomes 1AL, 1DS, 3AL, 4AL, 4BS, 6AL, and 7BS (Table 2; Fig. 2). Three of these QTL were detected in the combined analysis for both years. The QTL in chromosome 1AL is linked to marker wPt4399, the QTL in chromosome 6AL to DArT marker 378849 and the QTL in chromosome 4BS to marker wPt5265. These markers accounted for 12, 11, and 6\%, respectively, of the total $37 \%$ of phenotypic variance in Mt. Vernon (Table 3). The QTL identified on chromosomes 1DS, 3AL, 4AL, and 7BS were detected in one of the 2 years of testing, with phenotypic variance ranging from 6 to $11 \%$ (Table 2). At Mt. Vernon, all QTL were contributed by 'Stephens' with the exception of that on chromosome 6AL, which was contributed by 'Platte'.

QTL analysis for all locations except Mt. Vernon

QTL contributing to disease resistance at these locations were identified on chromosomes 2AS, 2BS (2 QTL), 4BL, 5AS, and 7AS (Fig. 3). The QTL detected over multiple locations included QYrst.orr-2AS, QYrst.orr-2BS.2, QYrst.orr-4BL, and QYrst.orr-7AS, explaining 19, 11, 9, and $15 \%$ of the phenotypic variance, respectively. Total phenotypic variance explained by these four QTL is approximately $50 \%$ (Table 3). QYrst.orr-2BS.2 linked to marker 
Table 2 QTL for stripe rust response at Mt. Vernon in 2008 and 2009, including position and peak on the linkage map, closest linked markers, likelihood odds (LOD) scores, estimated additive effects $(a)$, and phenotypic coefficients $\left(R^{2}\right)$

\begin{tabular}{|c|c|c|c|c|c|c|c|c|}
\hline \multirow[t]{2}{*}{ QTL Name } & \multirow{2}{*}{$\begin{array}{l}\text { QTL } \\
\text { peak cM }\end{array}$} & \multirow{2}{*}{$\begin{array}{l}\text { Closest } \\
\text { marker }\end{array}$} & \multicolumn{3}{|c|}{ Mt. Vernon 2008} & \multicolumn{3}{|c|}{ Mt. Vernon 2009} \\
\hline & & & LOD & $a$ & $R^{2}$ & LOD & $a$ & $R^{2}$ \\
\hline QYrst.orr-1AL & 17.8 & $w P t 4399$ & 6.8 & -10.8 & 14 & . & . & . \\
\hline QYrst.orr-3AL & 29.6 & $w P t 1652$ & 3.1 & -9.1 & 10 & . & . & . \\
\hline QYrst.orr- $4 A L$ & 44.8 & $w P t 9901$ & 3.0 & -7.6 & 7 & . & . & . \\
\hline QYrst.orr-7BS & 0.0 & $w P t 7653$ & 3.1 & -7.3 & 6 & . & . & . \\
\hline QYrst.orr-1DS & 23.0 & 379337 & . & . & . & 3.3 & -5.6 & 11 \\
\hline QYrpl.orr-6AL & 0.0 & 378849 & . & . & . & 3.0 & 4.2 & 6 \\
\hline QYrst.orr-4BS & 44.0 & $w P t 5265$ & 2.8 & -7.1 & 6 & 5.2 & -5.9 & 12 \\
\hline
\end{tabular}

Negative additive effect values indicate that the resistance allele is derived from 'Stephens'

Fig. 2 Linkage map with DArT markers showing chromosomes with QTL based on data sets from Mt. Vernon in 2008 and 2009
$1 \mathrm{~A}$

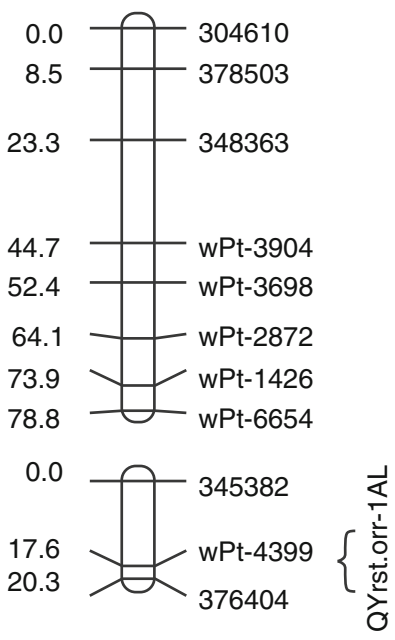

6A

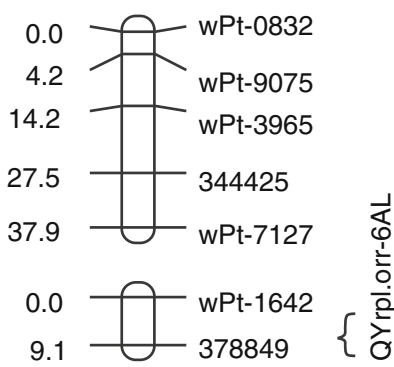

wPt0408 and QYrst.orr-7AS linked to DArT marker wPt4319 were detected in five environments. QYrst.orr$2 A S$, close to marker $w P t 0003$, was detected in four environments. QYrst.orr-4BL, linked to DArT marker 312980, was detected in three locations. QYrst.orr-2BS.1, linked to
1D

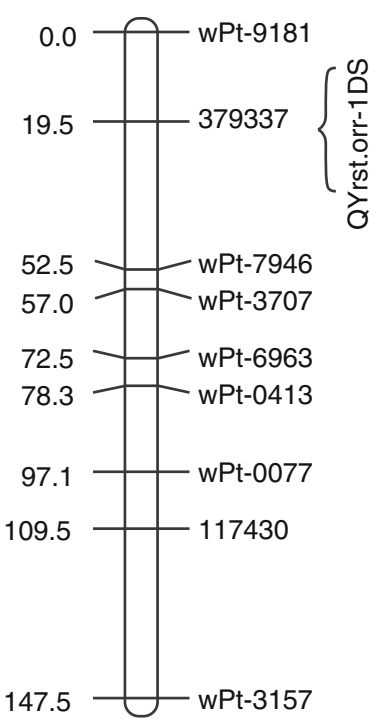

7B

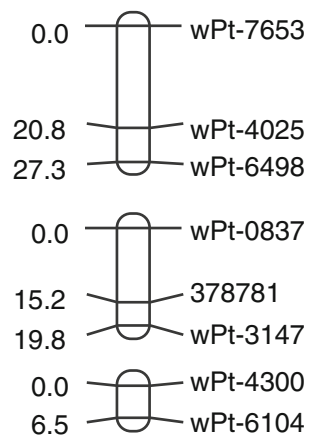

4A
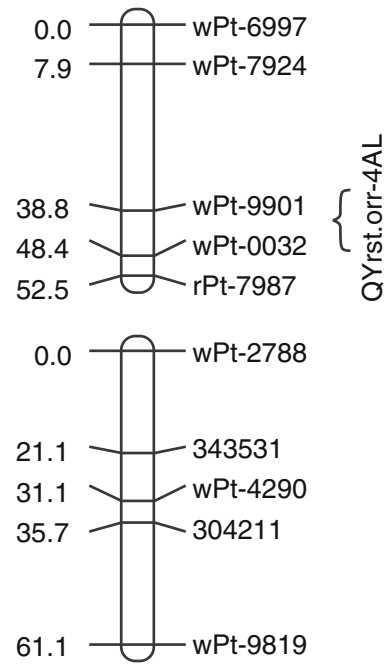

4B

marker wPt5738, was detected in two locations, while QYrst.orr-5AS, linked to DArT marker tPt4184, was detected in one location. All resistance QTL were contributed by 'Stephens' with the exception of QYrst.orr- $4 B L$ that was contributed by 'Platte'. 
Table 3 Combined QTL analysis associated with disease response for Mt. Vernon and the rest of the locations, including position and peak on the linkage map, closest linked markers, likelihood odds
(LOD) scores, estimated additive effects $(a)$, phenotypic coefficients $\left(R^{2}\right)$, and total phenotypic coefficients $\left(\mathrm{TR}^{2}\right)$

\begin{tabular}{|c|c|c|c|c|c|c|c|c|c|c|}
\hline \multirow[t]{2}{*}{ QTL name } & \multirow[t]{2}{*}{ QTL peak cM } & \multirow{2}{*}{$\begin{array}{l}\text { Closest } \\
\text { marker }\end{array}$} & \multicolumn{4}{|c|}{ Mt. Vernon } & \multicolumn{4}{|c|}{ All locations except Mt. Vernon } \\
\hline & & & LOD & $a$ & $R^{2}$ & $\mathrm{TR}^{2}$ & LOD & $a$ & $R^{2}$ & $\mathrm{TR}^{2}$ \\
\hline QYrst.orr-1AL & 16.0 & $w P t 4399$ & 5.2 & -7.2 & 12 & 38 & . & . & . & . \\
\hline QYrst.orr-4BS & 44.0 & $w P t 5265$ & 5.4 & -7.2 & 11 & 37 & . & . & . & . \\
\hline QYrpl.orr-6AL & 0.0 & 378849 & 3.1 & 5.2 & 6 & 36 & . & . & . & . \\
\hline QYrst.orr-2AS & 6.0 & $w P t 0003$ & . & . & . & . & 7.8 & -7.8 & 19 & 55 \\
\hline QYrst.orr-2BS.2 & 94.0 & $w P t 0408$ & . & . & . & . & 4.1 & -6.1 & 11 & 53 \\
\hline QYrst.orr-4BL & 0.0 & 312980 & . & . & . & . & 4.4 & 5.4 & 9 & 46 \\
\hline QYrst.orr-7AS & 2.0 & $w P t 4319$ & . & . & . & . & 8.4 & -7.1 & 15 & 49 \\
\hline
\end{tabular}

Negative additive effect values indicate that the resistance allele is derived from 'Stephens'

Fig. 3 Linkage map with DArT markers showing chromosomes with QTL detected at locations except Mt. Vernon
2A

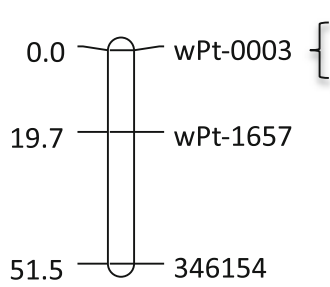

2B

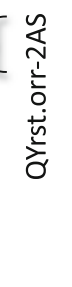

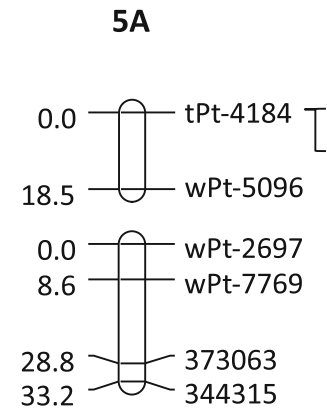

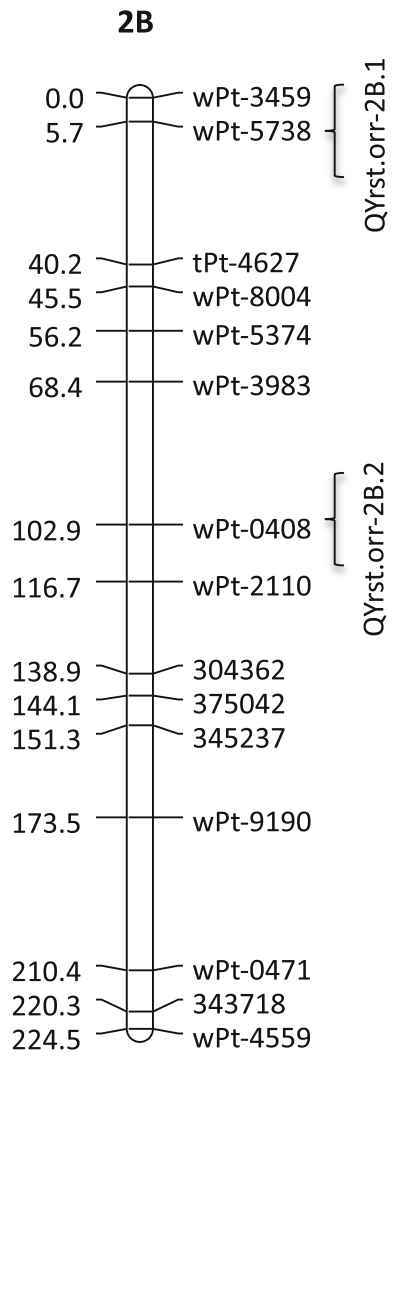

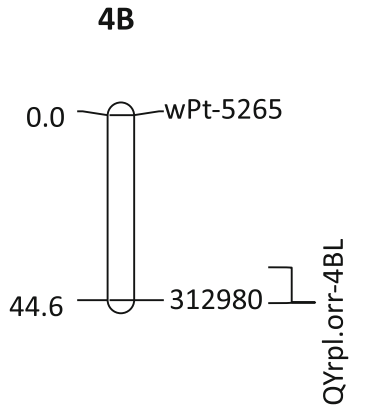

7A

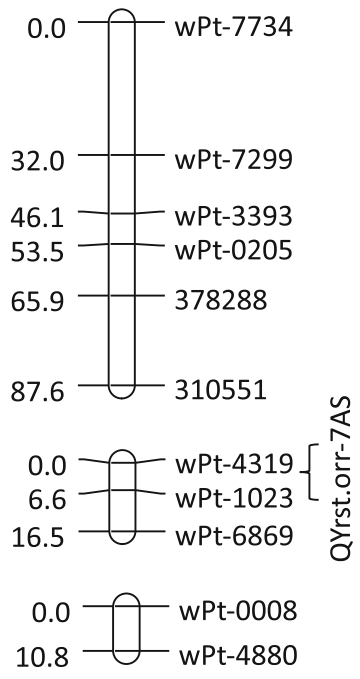

Of the 11 QTL identified in 'Stephens', only three were detected in four or more locations (excluding Mt. Vernon). These three QTL are QYrst.orr-2AS, QYrst.orr-2BS.2, and QYrst.orr-7AS, overall explaining 19, 11, and $15 \%$ of the phenotypic variance, respectively. These QTL were detected at Corvallis, Pendleton, and Toluca (Table 4). Based on these three QTL, a simulation for additive interactions was done in SAS version 9.1.3 (SAS Institute, 
Table 4 QTL associated with disease response for all locations except Mt. Vernon, including position and peak on the linkage map, closest linked markers, likelihood odds (LOD) scores, estimated additive effects $(a)$, and phenotypic coefficients $\left(R^{2}\right)$

\begin{tabular}{|c|c|c|c|c|c|c|}
\hline QTL name & QYrst.orr-2BS.2 & QYrst.orr-7AS & QYrst.orr-2AS & QYrpl.orr- $4 B L$ & QYrst.orr-2BS.1 & QYrst.orr-5AS \\
\hline QTL peak cM & 96.0 & 2.0 & 6.0 & 0.0 & 9.7 & 2.0 \\
\hline Closest marker & wPt0408 & $w P t 4319$ & wPt0003 & 312980 & $w P t 5738$ & tpt4184 \\
\hline \multicolumn{7}{|l|}{ Toluca 2008} \\
\hline LOD & 3.2 & 5.9 & 3.8 & 4.50 & . & . \\
\hline$a$ & -5.3 & -6.4 & -5.5 & 5.40 & . & . \\
\hline$R^{2}$ & 9.0 & 13.0 & 9.0 & 9.00 & . & . \\
\hline \multicolumn{7}{|l|}{ Toluca 2009} \\
\hline LOD & 2.7 & 5.7 & . & . & . & . \\
\hline$a$ & -3.0 & -3.0 & . & . & . & . \\
\hline$R^{2}$ & 10.0 & 13.0 & . & . & . & . \\
\hline \multicolumn{7}{|l|}{ Corvallis 2008} \\
\hline LOD & 2.8 & 6.1 & 5.2 & 5.0 & . & . \\
\hline$a$ & -8.2 & -10.1 & -11.5 & 9.4 & . & . \\
\hline$R^{2}$ & 8.0 & 12.0 & 15.0 & 10.0 & . & . \\
\hline \multicolumn{7}{|l|}{ Corvallis 2009} \\
\hline LOD & 4.3 & 10.0 & 6.7 & . & . & . \\
\hline$a$ & -7.9 & -12.1 & -9.7 & . & . & . \\
\hline$R^{2}$ & 8.0 & 20.0 & 13.0 & . & . & . \\
\hline \multicolumn{7}{|l|}{ Pendleton 2008} \\
\hline LOD & 3.1 & 5.2 & 5.9 & . & 3.0 & . \\
\hline$a$ & -6.2 & -6.1 & -7.9 & . & -5.5 & . \\
\hline$R^{2}$ & 13.0 & 12.0 & 20.0 & . & 10.0 & . \\
\hline \multicolumn{7}{|l|}{ Whitlow 2008} \\
\hline LOD & . & . & . & 4.90 & 3.6 & 3.80 \\
\hline$a$ & . & . & . & 4.50 & -4.4 & -4.30 \\
\hline$R^{2}$ & . & . & . & 11.00 & 10.0 & 10.00 \\
\hline
\end{tabular}

Negative additive effect values indicate that the resistance allele is derived from 'Stephens'

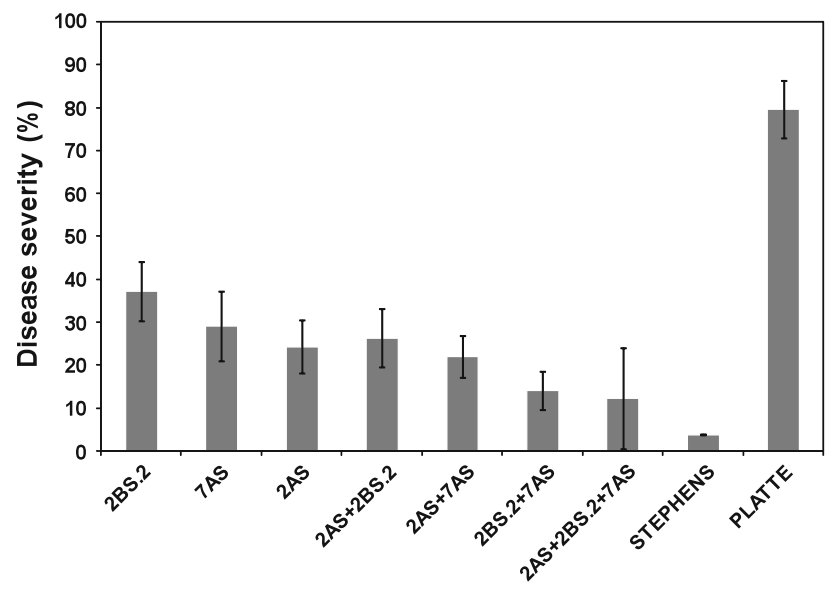

Fig. 4 QTL combinations and their confidence intervals with three QTL found in this study and their possible effect on stripe rust severity averaged across all locations. All three QTL were contributed by 'Stephens'

Inc., Cary, NC, USA). An additive interaction is seen for QYrst.orr-2BS.2 + QYrst.orr-7AS, but when QYrst.orr-2AS, QYrst.orr-2BS.2, and QYrst.orr-7AS are combined, there is higher variability in disease response (Fig. 4). All data were analyzed for epistasis with the IMI procedure in QTL Cartographer v.2.5, but no significant results were found.

\section{Discussion}

Resistance to wheat stripe rust is often described with regard to the plant growth stage at which it is expressed and the effects of temperature on expression (Chen 2005). In most of the locations, disease occurred only in the adult plant stages. In other cases (Mt. Vernon), heavy seedling epidemics could have interfered with the detection of adult plant resistance QTL by masking the effect of minor genes. In no case did we have a method to determine the effect of temperature on the expression of resistance. Though resistance of 'Stephens' wheat can be considered durable sensu Johnson (1981), we cannot determine if the QTL we identified will be durable in other combinations of QTL or in different genetic backgrounds. Given these complications, we consider the QTL that we identified in this paper 
Table 5 Summary of QTL identified, closest DArT marker, and relationship to previous studies of wheat stripe rust resistance

\begin{tabular}{|c|c|c|c|}
\hline Chromosome & $\begin{array}{l}\text { DArT marker } \\
\text { associated }\end{array}$ & QTL name & References \\
\hline $1 \mathrm{~A}$ & $w P t 4399$ & QYrst.orr-1AL & Chen et al. (1995) (YrDa1); Crossa et al. (2007) \\
\hline $1 \mathrm{D}$ & $379331 / w P t 7946$ & QYrst.orr-1DS & Calonnec and Johnson (1998) (Yr25); Crossa et al. (2007) \\
\hline $2 \mathrm{~A}$ & $w P t 0003 / w P t 1657$ & QYrst.orr- $2 A S$ & $\begin{array}{l}\text { Bariana and McIntosh (1993) (Yr17); Boukhatem et al. (2002), Chhuneja } \\
\text { et al. (2008); Crossa et al. (2007), Eriksen et al. (2004) (Yr32); Mallarc } \\
\text { et al. (2005) }\end{array}$ \\
\hline 2B & $\begin{array}{l}w P t 5738 \\
w P t 0408\end{array}$ & $\begin{array}{l}\text { QYrst.orr-2BS.1 } \\
\text { QYrst.orr-2BS.2 }\end{array}$ & $\begin{array}{l}\text { Bariana et al. (2001); Börner et al. (2002); Boukhatem et al. (2002); } \\
\text { Crossa et al. (2007); Dedryver et al. (2009); Guo et al. (2008); Luo et al } \\
\text { (2005); Mallard et al. (2005); McDonald et al. } 2004 \text { (Yr27, Yr31); } \\
\text { Rosewarne et al. 2008 (Yr5, Yr7, Yr27); Zhang et al. (2009) (Yr5, Yr7) }\end{array}$ \\
\hline $3 \mathrm{~A}$ & $w P t 1652$ & QYrst.orr- $3 A L$ & Chen et al. (1995) ( $Y r T r 2)$; Crossa et al. (2007) \\
\hline $4 \mathrm{~A}$ & $w P t 0032$ & QYrst.orr- $4 A L$ & Chen et al. (1995) (YrHVII, YrMin); Crossa et al. (2007) \\
\hline 4B & 312980 & QYrst.orr- $4 B L$ & $\begin{array}{l}\text { Chen et al. (1995) (YrCle, YrMor and YrYam); Crossa et al. (2007); Lu } \\
\text { et al. (2009); Suenaga et al. (2003) }\end{array}$ \\
\hline $5 \mathrm{~A}$ & $t P t-4184$ & QYrst.orr-5AS & $\begin{array}{l}\text { Bariana et al. (2006) (Yr34); Boukhatem et al. (2002); Crossa et al. } \\
\text { (2007); Calonnec and Johnson (1998) }\end{array}$ \\
\hline $6 \mathrm{~A}$ & 378849 & QYrst.orr-6AL & Lillemo et al. (2008); Marais et al. (2006) (Yr38); Crossa et al. 2007 \\
\hline $7 \mathrm{~A}$ & $w P t 4319$ & QYrst.orr-7AS & Börner et al. (2002); Crossa et al. (2007) \\
\hline $7 \mathrm{~B}$ & $w P t 7653$ & QYrst.orr-7BS & $\begin{array}{l}\text { Crossa et al. (2007) (Yr2, Yr6, Yr39); Rosewarne et al. (2008); Suenaga } \\
\text { et al. (2003) }\end{array}$ \\
\hline
\end{tabular}

as contributing to quantitative resistance, but also that QYrst.orr-2AS, QYrst.orr-2BS.2, and QYrst.orr-7AS may have special importance because of their constant detection in more than four locations.

Some QTL combinations appear to have an additive resistance effect, especially QYrst.orr-2BS.2 and QYrst.orr$7 A S$. Lines carrying just one of these QTL did not seem to be as resistant as lines identified with both QTL or in other combinations. QYrst.orr-2BS.2 showed an increased additive effect with advancing plant age (data not shown). However, this effect was not observed for the QTL in chromosome $2 \mathrm{AS}$ and $7 \mathrm{AS}$; their additive effect seemed stable over time. The remaining QTL detected in only one or two locations were identified in 'Platte'. There was no opportunity to draw strong conclusions regarding temporal expression of resistance of these QTL.

\section{Disease response in two mega-environments}

In the present study, many QTL contributing to the stripe rust resistance of 'Stephens' were detected. QTL detected in Mt. Vernon were clearly different from those detected in the remaining locations. A unique response in the Mt. Vernon location was reported previously for barley stripe rust, caused by $P$. striiformis f. sp. hordei (Vales et al. 2005). Because of the mild climate all year long and its separation from the inland Pacific Northwest by the Cascade Mountains, Mt. Vernon is known to produce its own stripe rust inoculum and infections at the seedling stage are common. Mt. Vernon is a relatively small wheat-producing region and stripe rust races present at this location are more diverse when compared with the other locations (Chen 2005). The presence of seedling resistance genes and diverse races may result in different QTL being identified at this site. Relatively low temperatures and frequent dew formation make 'Stephens' less resistant in Mt. Vernon than in other locations (Chen and Line 1995a, b).

Santra et al. (2008) reported that a QTL on chromosome 6BS was mainly responsible for the resistance in 'Stephens' in Mt. Vernon. They also suggested that this QTL was of the HTAP resistance type, i.e., resistance that is expressed at the adult plant stage and when weather becomes warm (Qayoum and Line 1985). In this study, we did not detect a QTL on chromosome 6BS despite the fact that we evaluated markers that cover the region in which the 6BS QTL was reported to reside. The presence of seedling epidemics could have interfered with the detection of high-temperature QTL in chromosome 6B in our experiment. Also, the QTL and/or alleles contributed by the susceptible parent 'Platte' could have interfered in the expression of this QTL. Furthermore, 'Stephens' is known to be a heterogeneous cultivar (Kronstad et al. 1978) and the 'Stephens' plant used as the parent for the RILs in this study could be a different genotype compared to the one used by Santra et al. (2008).

A large number of wheat stripe rust resistance QTL have been reported in the same chromosome regions as in our study (Table 5). Given the inability of QTL analyses to 
provide precise chromosomal positions, it is uncertain whether the QTL being reported in this study are the same as those identified in other studies or if they are components of a common region rich in rust resistance genes (e.g., Boukhatem et al. 2002; McDonald et al. 2004).

\section{Summary and implications for breeding}

From the 13 QTL identified, 7 were seen at one location/year. Those were located in chromosomes 1AL, 3AL, 4AL, 7BS, 1DS, 6AL, and 5AS. The phenotypic variances explained by each of these 7 QTL were in the range of 6-14\%. Two QTL, QYrst.orr-4BS and QYrst.orr-2BS.1, were detected at two locations and explained between 6 and $12 \%$ of the phenotypic variance. QYrst.orr-4BL was detected at three locations explaining between 9 and $11 \%$ of the phenotypic variance. QYrst.orr-2AS was detected in four locations and explained between 9 and $20 \%$ of the phenotypic variance. QYrst.orr$2 B S .2$ and QYrst.orr-7AS were detected in five locations. The phenotypic variance explained by QYrst.orr-2BS.2 was between 8 and $13 \%$. QYrst.orr-7AS explained $12-20 \%$ of the phenotypic variance. None of the QTL identified in this study had an additive effect larger than 12 or explained more than $20 \%$ of the phenotypic variance. Although a high number of QTL were found in the study, only $65 \%$ of the phenotypic variance (resistance) was explained when accounting for all environments.

In total, we identified 13 QTL that provide resistance to stripe rust in this population, and 11 came from 'Stephens'. Thus, 'Stephens' could possess a unique configuration of genes, with additive effects, which are responsible for its durable resistance. Furthermore, none of the QTL detected in this study for the Oregon and Washington locations can be attributed to race-specific seedling resistance as almost all races detected in these locations in 2008 and 2009 are virulent on seedlings of 'Stephens' (X.M. Chen and A. Wan, unpublished data). Chen and Line (1995a, b) reported the presence of two-to-three HTAP resistance genes behind the durable resistance in 'Stephens'. In addition, combinations of seedling and adult plant resistance genes are thought to be responsible for the resistance that 'Stephens' has shown over the past 30 years (Chen 2005). Still, in recent years, the resistance of 'Stephens' in the Pacific Northwest has been largely contributed by HTAP resistance. Thus, determining the relationship between the QTL detected in this study and HTAP-type resistance would provide additional insights into the durable resistance of 'Stephens'.

Although we detected many QTL for stripe rust resistance located in similar positions to those reported by others (Table 5), questions still remain regarding the usefulness of MAS for this trait because of the number of factors involved and uncertainties related to the expression of these QTL in multiple genetic backgrounds and the interaction of these QTL when pyramided with other adult plant resistance genes. Although Singh et al. (2009) recently concluded that three-to-five additive genes (mainly slow-rusting genes) could provide durable resistance in wheat cultivars, not impossible to achieve in a MAS program, population sizes larger than that used in our study may be required to identify a sufficient number of lines with combinations of QTL that provide high levels of resistance.

\section{References}

Akbari M, Wenzl P, Caig V, Carling J, Xia L, Yang S, Uszynski G, Mohler V, Lehmensiek A, Kuchel H, Hayden MJ, Howes N, Sharp P, Vaughan P, Rathmell B, Huttner E, Kilian A (2006) Diversity arrays technology (DArT) for high-throughput profiling of the hexaploid wheat genome. Theor Appl Genet 113:1409-1420

Bariana HS, McIntosh RA (1993) Cytogenetic studies in wheat XV. Location of rust resistance genes in VPM1 and their genetic linkage with other resistance genes in chromosome $2 \mathrm{~A}$. Genome 36:476-482

Bariana HS, Hayden MJ, Ahmed NU, Bell JA, Sharp PJ, McIntosh RA (2001) Mapping of durable adult plant and seedling resistances to stripe rust and stem rust diseases in wheat. Aust J Agric Res 52:1247-1255

Bariana HS, Parry N, Barclay IR, Loughman R, McLean RJ, Shankar M, Wilson RE, Willey NJ, Francki M (2006) Identification and characterization of stripe rust resistance gene $\mathrm{Yr} 34$ in common wheat. Theor Appl Genet 112:1143-1148

Börner A, Schumann E, Fürste A, Cöster H, Leithold B, Röder MS, Weber WE (2002) Mapping of quantitative trait loci determining agronomic important characters in hexaploid wheat (Triticum aestivum L.). Theor Appl Genet 105:921-936

Boukhatem N, Baret PV, Mingeot D, Jacquemin JM (2002) Quantitative trait loci for resistance against yellow rust in two wheatderived recombinant inbred line populations. Theor Appl Genet 104:111-118

Calonnec A, Johnson R (1998) Chromosomal location of genes for resistance to Puccinia striiformis in the wheat line TP1295 selected from the cross of Soissonais-Desprez with Lemhi. Eur J Plant Pathol 104:835-847

Chen XM (2005) Epidemiology and control of stripe rust [Puccinia striiformis f. sp. tritici] on wheat. Can J Plant Pathol 27:314-337

Chen XM, Line RF (1995a) Gene action in wheat cultivars for durable, high-temperature, adult-plant resistance and interaction with race-specific, seedling resistance to Puccinia striiformis. Phytopathology 85:567-572

Chen XM, Line RF (1995b) Gene number and heritability of wheat cultivars with durable, high-temperature, adult-plant resistance and race-specific resistance to Puccinia striiformis. Phytopathology 85:573-578

Chen XM, Line RF, Jones SS (1995) Chromosomal location of genes for resistance to Puccinia striiformis in winter wheat cultivars Heines VII, Clement, Moro, Tyee, Tres and Daws. Phytopathology 85:1362-1367

Chhuneja P, Kaur S, Garg T, Ghai M, Kaur S, Prashar M, Bains NS, Goel RK, Keller B, Dhaliwal HS, Singh K (2008) Mapping of adult plant stripe rust resistance genes in diploid A genome wheat species and their transfer to bread wheat. Theor Appl Genet 116:313-324 
Churchill G, Doerge RW (1994) Empirical threshold values for quantitative trait mapping. Genetics 138:963-971

Crossa J, Burgueño J, Dreisigacker S, Vargas M, Herrera-Foessel SA, Lillemo M, Singh RP, Trethowan R, Warburton M, Franco J, Reynolds M, Crouch JH, Ortiz R (2007) Association analysis of historical bread wheat germplasm using additive genetic covariance of relatives and population structure. Genetics 177:1889-1913

Dedryver F, Paillard S, Mallard S, Robert O, Trottet M, Nègre S, Verplancke G, Jahier J (2009) Characterization of genetic components involved in durable resistance to stripe rust in the bread wheat "Renan". Phytopathology 99:968-973

Eriksen L, Afshari F, Christiansen MJ, McIntosh RA, Jahoor A, Wellings CR (2004) Yr32 for resistance to stripe (yellow) rust present in the wheat cultivar Carstens V. Theor Appl Genet 108:567-575

GrainGenes 2.0 (2009) A database for Triticeae and Avena maps. http://wheat.pw.usda.gov/ggpages/map_shortlist.html. Accessed on November 232009

Guo Q, Zhang ZJ, Xu YB, Li GH, Feng J, Zhou Y (2008) Quantitative trait loci for high-temperature adult-plant and slow-rusting resistance to Puccinia striiformis $\mathrm{f}$ sp tritici in wheat cultivars. Phytopatology 98:803-809

Haldane JBS (1919) The combination of linkage values, and the calculation of distances between the loci of linked factors. J Genet 8:299-309

Holland JB, Nyquist WE, Cervantes-Martinez CT (2003) Estimating and interpreting heritability for plant breeding: An update. Plant Breeding Rev 22:9-112

Hovmøller MS, Yahyaoui AH, Milus EA, Justesen AF (2008) Rapid global spread of two aggressive strains of a wheat rust fungus. Mol Ecol 17:3818-3826

Johnson R (1981) Durable resistance: definition of, genetic control, and attainment in plant breeding. Phytopathology 71:567-568

Kronstad WE, Rohde CR, Kolding MF, Metzger RJ (1978) Registration of Stephens wheat. Crop Sci 18:1097

Leonard JM, Watson CJ, Carter AH, Hansen JL, Zemetra RS, Santra DK, Garland Campbell KA, Riera-Lizarazu O (2008) Identification of a candidate gene for the wheat endopeptidase Ep-D1 locus and two other STS markers linked to the eyespot resistance gene Pchl. Theor Appl Genet 116:261-270

Li ZF, Xia XC, Zhou XC, Niu YC, He ZH, Zhang Y, Li GQ, Wan AM, Wang DS, Chen XM, Lu QL, Singh RP (2006) Seedling and slow rusting resistance to stripe rust in Chinese common wheats. Plant Dis 90:1302-1312

Lillemo M, Asalf B, Singh RP, Huerta-Espino J, Chen XM, He ZH, Bjørnstad $\AA$ (2008) The adult plant rust resistance loci Lr34/Yr18 and $L r 46 / Y r 29$ are important determinants of partial resistance to powdery mildew in bread wheat line Saar. Theor Appl Genet 116:1155-1166

Lu Y, Lan C, Liang S, Zhou X, Liu D, Zhou G, Lu Q, Jing J, Wang M, Xia X, He Z (2009) QTL mapping for adult-plant resistance to stripe rust in Italian common wheat cultivars Libellula and Strampelli. Theor Appl Genet 119:1349-1359

Luo PG, Ren ZL, Zhang HQ, Zhang HY (2005) Identification, chromosome location, and diagnostic markers for a new gene ( $\mathrm{YrCN19)}$ for resistance to wheat stripe rust. Phytopathology 95:1266-1270

Mallard S, Gaudet D, Aldeia A, Abelard C, Besnard AL, Sourdille P, Dedryver F (2005) Genetic analysis of durable resistance to yellow rust in bread wheat. Theor Appl Genet 110:1401-1409

Marais GF, McCallum B, Marais AS (2006) Leaf rust and stripe rust resistance genes derived from Aegilops sharonensis. Euphytica 149:373-380
Markell SG, Milus EA (2008) Emergence of a novel population of Puccinia striiformis f. sp. tritici in eastern United States. Phytopathology 98:632-639

McDonald DB, McIntosh RA, Wellings CR, Singh RP, Nelson JC (2004) Cytogenetical studies in wheat XIX Location and linkage studies on gene $\operatorname{Yr} 27$ for resistance to stripe (yellow) rust. Euphytica 136:239-248

Milus EA, Seyran E, McNew R (2006) Aggressiveness of Puccinia striiformis $\mathrm{f}$ sp. tritici isolates in the south-central United States. Plant Dis 90:847-852

Milus EA, Kristensen K, Hovmøller MS (2009) Evidence for increased aggressiveness in a recent widespread strain of Puccinia striiformis f. sp. tritici causing stripe rust of wheat. Phytopathology 99:89-94

Niks RE, Rubiales D (2002) Potentially durable resistance mechanisms in plants to specialised fungal pathogens. Euphytica 124:201-216

Qayoum A, Line RF (1985) High-temperature, adult-plant resistance to stripe rust of wheat. Phytopathology 75:1121-1125

Riera-Lizarazu O, Vales IM, Ananiev EV, Rines HW, Phillips RL (2000) Production and characterization of maize chromosome radiation hybrids derived from an oat-maize addition line. Genetics 156:329-339

Roelfs AP, Singh RP, Saari EE (1992) Rust diseases of wheat: concepts and methods of disease management Mexico, DF, CIMMYT pp 45

Rosewarne GM, Singh RP, Huerta-Espino J, Rebetzke GJ (2008) Quantitative trait loci for slow-rusting resistance in wheat to leaf rust and stripe rust identified with multi-environment analysis. Theor Appl Genet 116:1027-1034

Santra DK, Chen XM, Santra M, Campbell KG, Kidwell KK (2008) Identification and mapping QTL for high-temperature adult-plant resistance to stripe rust in winter wheat (Triticum aestivum L.) cultivar Stephens. Theor Appl Genet 117:793-802

SAS 9132005 Institute Inc SAS software, Version 913 Cary, NC, USA: SAS Institute Inc 2000

Singh RP, Huerta-Espino J, Bhavani S, Singh D, Singh PK, HerreraFoessel SA, Njau P, Wanyera R, Jin Y (2009) Breeding for minor gene-based adult plant resistance to stem rust in wheat. In: Borlaug global rust initiative, technical workshop Cd Obregon, Sonora, Mexico, March 17-20, 2009, pp 67

Suenaga K, Singh RP, Huerta-Espino J, William HM (2003) Microsatellite markers for genes $\operatorname{Lr} 34 / \mathrm{Yr} 18$ and other quantitative trait loci for leaf rust and stripe rust resistance in bread wheat. Phytopathology 93:881-890

Tang S, Leon A, Bridges WC, Knapp SJ (2006) Quantitative trait loci for genetically correlated seed traits are tightly linked to branching and pericarp pigment loci in sunflower. Crop Sci 46:721-734

Triticarte (2009) Wheat DArT ${ }^{\circledR}$ Yarralumla ACT 2600 Australia. http://www.triticarte.com.au/content/wheat_diversity_analysis. html. Accessed on April 23, 2009

USDA-AMS (2009) Plant Variety Protection Office Beltsville, MD. http://www.ars-grin.gov/cgi-bin/npgs/html/pvplist.pl? Accessed on April 232009

Vales MI, Schön CC, Capettini F, Chen XM, Corey AE, Mather DE, Mundt CC, Richardson KL, Sandoval-Islas JS, Utz HF, Hayes PM (2005) Effect of population size on the estimation of QTL: A test using resistance to barley stripe rust. Theor Appl Genet 111:1260-1270

Van Ooijen JW, Voorrips RE (2001) JoinMap ${ }^{\circledR}$ version 40: software for the calculation of genetic linkage maps. Plant Research International, Wageningen

Wang S, Basten CJ, Zeng Z-B (2007) Windows QTL Cartographer 25. Department of Statistics. North Carolina State University, Raleigh 
Wheat Pedigree On Line (2009) Wheat pedigree and identified alleles of genes on line. http://genbank.vurv.cz/wheat/pedigree/ pedigree.asp. Accessed on April 23, 2009

Yan W, Kang MS (2003) GGE biplot analysis: a graphical tool for breeders, geneticists, and agronomists. CRC Press, Boca Raton
Yang R-C, Crossa J, Cornelius PL, Burgueño J (2009) Biplot analysis of genotype $\times$ environment interaction: proceed with caution. Crop Sci 49:1564-1576

Zhang P, McIntosh RA, Hoxha S, Dong C (2009) Wheat stripe rust resistance genes $\mathrm{Yr} 5$ and $\mathrm{Yr} 7$ are allelic. Theor Appl Genet 120:25-29 